\title{
Specific Detection of Bovine Coronavirus N Protein with TaqMan Probe qRT-PCR
}

\author{
Jin-jing Geng ${ }^{1,2}$, Zhuan-di Gong ${ }^{3}$, Qiong-yi Li' ${ }^{2}$ Xiao-yun Shen ${ }^{4}$ \& Suo-cheng Wei ${ }^{1,2}$
}

\begin{abstract}
Background: Bovine Coronavirus (BCoV) can cause acute diarrhea in newborn calves and adult cattle. $\mathrm{BCoV}$ infection may cause losses to production by reduced weight gain and milk yield of the infected animals. Several methods have been applied to detect and diagnose BCoV. However, each assay has its deficiency. Currently, real-time quantitative PCR (qRTPCR) has been utilized to identify and quantify many viral pathogens since it is a highly sensitive. However, the technical assay varies due to normalization control of the signal with an internal standard, typically a housekeeping gene.

Materials, Methods \& Results: The present study was aimed to establish a novel TaqMan probe real-time PCR (qRT-PCR) for detecting bovine coronaviruses $(\mathrm{BCoV})$, and also to develop a diagnostic protocol which simplifies sample collection and processing. One pair of specific primers, one pair of universal primers and a TaqMan probe were designed from the known sequences of conserved nucleocapsid $(\mathrm{N})$ protein of BCoV. Reaction systems of TaqMan qRT-PCR were optimized including concentrations of the primers and probe as well as annealing temperatures. Prior to optimizing the assay, the recombinant plasmids of pMD18-T-BCoV-N were successfully constructed to make standard curves. The sensitivity, specificity and reproducibility were evaluated on the TaqMan qRT-PCR, respectively. A total of 321 feces specimens collected from diarrheic calves were detected with this assay. The results showed the optimized reaction conditions for qRT-PCR were $14.5 \mu \mathrm{M} / \mathrm{L}$ primers, $19.5 \mu \mathrm{M} / \mathrm{L}$ probes and $45.0^{\circ} \mathrm{C}$ annealing temperatures. The established TaqMan qRT-PCR assay could specially detect $\mathrm{BCoV}$ without detecting any other viruses. Its minimum detection limit was $4.72 \times 10^{1} \mathrm{copies} / \mu \mathrm{L}$. However, universal PCR could detect only $4.72 \times 10^{3}$ copies/ $\mu$ L. Its sensitivity was 100 -fold stronger than universal PCR. In conclusion, this TaqMan qRT-PCR had excellent specificity, sensitivity and stability with a 100-fold sensitivity stronger than universal PCR. Minimum detection limit was $4.72 \times 10^{1}$ copies/ $\mu \mathrm{L}$. This method was a cost-effective method to diagnose diarrhea and distinguish pathogens in dairy farms.

Discussion: In this study, the authors developed a quantitative real-time PCR (qRT-PCR) based on the TaqMan probe of BCoV. This TaqMan qRT-PCR assay selected and used one pair of specific primers (BCoV-qF/BCoV-qR) and a specific TaqMan probe (BCoV-probe) targeting the conserved nucleocapsid $(\mathrm{N})$ gene. The specificity of primers and probes was validated with Primer-BLAST. The specificity of the qRT-PCR was confirmed by the negative control and other six viruses. The findings demonstrated that TaqMan qRT-PCR could only detect BCoV. This verified the qRT-PCR had an excellent specificity. It was testified that this TaqMan qRT-PCR assay can detect only BCoV with stronger sensitivity and reproducibility than universal PCR methods. The sensitivity test indicated the minimum detection limit of the TaqMan qRT-PCR was $4.72 \times 10^{1}$ copies $/ \mu \mathrm{L}$, or 47.2 copies/ $\mu \mathrm{L}$. Sensitivity of the TaqMan qRT-PCR assay was increased by 100 -fold as compared to universal PCR with a good inter-assay and intra-assay reproducibility. Thereby, based on the high sensitivity of the assay of this qRT-PCR assay it may be a cost-effective method to diagnose BCoV infections and indentify the etiologic agents of diarrhea syndrome in the dairy farms.
\end{abstract}

Keywords: bovine coronaviruses, nucleocapsid protein, quantitative real-time PCR, TaqMan probe, diarrhea, calves. 


\section{INTRODUCTION}

Neonatal calf diarrhea (NCD) is a major cause of morbidity, mortality and economic losses in cattle farms [16]. Bovine coronavirus (BCoV) is an important pathogen of NCD worldwide. Coronaviruses contains a positive sense single stranded RNA genome, coding for five major structural proteins: including the nucleocapsid $(\mathrm{N})$, spike $(\mathrm{S})$ and non-structural proteins $[18,19,23]$.

BCoV infection may cause losses to production by reduced weight gain [9] and milk yield [3, $22]$. BCoV was detected in $18.95 \%(36 / 190)$ of the samples by reverse transcriptase polymerase chain reaction in China. $\mathrm{BCoV}$ also resulted in yak diarrhea of China [10]. BCoV was more likely to be detected in diarrheic calves than healthy calves [7]. It is very urgent to early diagnose and control dairy calves diarrhea [12]. However, there are few reports on Mecular characterization of bovine coronavirus, and little data exists apart from serological studies $[7,8]$.

Several methods have been applied to detect and diagnose $\mathrm{BCoV}$, such as viral culture, antigencapture ELISA, hemagglutination assay and PCR $[4,21]$. The universal PCR was reported for the detection of several animal and human viruses $[5,17]$. The real-time quantitative PCR (qPCR) has been utilized to identify, genetype and quantify many viral pathogens since it is a highly sensitive $[14,25]$. However, this technique differed in the sensitivity and specificity among the different reports [24]. To circumvent these limitations, The aim of the present study was to develop a qRT-PCR based on the TaqMan probe, additionally to establish an accurate and rapidly method for detecting $\mathrm{BCoV}$.

\section{MATERIALS AND METHODS}

RNA extraction from feces samples and BCoV SWMU strains

A total of 321 feces samples collected from the calves (less than 6 months old) with obvious diarrhea from six different cattle farms in Gansu Province of China. Feces samples were fully resuspended in phosphate-buffered saline $(1: 5 \mathrm{w} / \mathrm{v})$ and centrifuged at $8000 \mathrm{~g}$ for $10 \mathrm{~min}$. Total viral RNA was extracted from the using the TIANamp Virus RNA Kit ${ }^{1}$ complying with the manufacturer's protocol.

The fragments were cloned into the pMD$18 \mathrm{~T}$ vector $^{2}$. The recombinant plasmids were used as standards in real-time RT-PCR. The plasmids were quantified using the following formula: $\mathrm{Y}$ (copies/ $\mu \mathrm{L}$ ) $=[$ concentration of plasmid DNA $(\mathrm{g} / \mu \mathrm{L}) /$ plasmid DNA length $(\mathrm{bp}) \times 660] \times 6.02 \times 10^{23}[26]$. The cDNA was synthesized using the PrimeScript ${ }^{\mathrm{TM}}$ RT Reagent kit $^{3}$ according to the manufacturer's instructions, and then stored at $-80^{\circ} \mathrm{C}$ for the subsequent tests.

\section{Primers and probe design}

The full-length genome of the nucleocapsid (N) protein of $\mathrm{BCoV}$ was obtained from the GenBank database (Gene Accession No: MK095166, KT318096.1, FJ938064, KT318094.1). We designed one pair of universal primers (BCoV-F/BCoV-R), one pair of specific primers (BCoV-qF/BCoV-qR) and a specific TaqMan probe (BCoV-probe) according to the gene sequence of BCoV N protein using Primer 7.0 software. Both 5'-end and 3 '-end of the $\mathrm{BCoV}$-probe were labeled with $\mathrm{CY} 3$ and BHQ2, respectively. The specificity of the designed primers and probes was verified with Primer-BLAST on NCBI online. The primers and probes were synthesized by the TAKARA Bio Inc4 (Table 1).

Table 1. Primer and probe sequences for qRT-PCR.

\begin{tabular}{|c|c|c|c|c|c|}
\hline Primer & Primer sequences $\left(5^{\prime} \rightarrow 3^{\prime}\right)$ & $\mathrm{Tm}$ & $\begin{array}{l}\text { Frame } \\
\text { length }\end{array}$ & $\mathrm{CG}$ & Product length/bp \\
\hline $\begin{array}{c}\text { BCoV-F } \\
(509-531)\end{array}$ & AGGCTATTCCGACTAGGTTTCCG & 63.2 & $23 \mathrm{bp}$ & $52.2 \%$ & \multirow{2}{*}{699} \\
\hline $\begin{array}{c}\text { BCoV-R } \\
(1185-1207)\end{array}$ & GTCCRTTCTTCTGRCCRCGMTGA & 66.2 & $23 \mathrm{bp}$ & $56.5 \%$ & \\
\hline $\mathrm{BCoV}-\mathrm{qF}$ & TGCTCCTAATTCCAGATC & 59.5 & $18 \mathrm{bp}$ & $44.4 \%$ & \multirow{3}{*}{194} \\
\hline BCoV-qR & CAGTCTGCTTAGTTACTTG & 59.1 & $19 \mathrm{bp}$ & $42.1 \%$ & \\
\hline BCoV-probe & CY3-CGCATCCAGTAGAGCCTCTAGTG-BHQ2 & 69.1 & $23 \mathrm{bp}$ & $56.5 \%$ & \\
\hline
\end{tabular}


Construction of standard plasmids and copies

The cDNAs were amplified by PCR using universal primers. Fifty $\mu \mathrm{L}$ PCR reaction system included $0.5 \mu \mathrm{L}$ Takara LA Taq (5 IU/ $\mu \mathrm{L}), 10 \times$ LA PCR Buffer (Mg2+ plus, $8 \mu \mathrm{L}$ dNTP Mixture $(2.5 \mathrm{mM}) 5 \mu \mathrm{L}$, BCoVF $1 \mu \mathrm{L}$, L BCoV-R $1 \mu \mathrm{L}$, template cDNAs $5 \mu \mathrm{L}$ and diethyl pyrocarbonate (DEPC) water. Reaction conditions were $94^{\circ} \mathrm{C}$ for $5 \mathrm{~min}, 94^{\circ} \mathrm{C}$ for $30 \mathrm{~s}, 60^{\circ} \mathrm{C}$ for $45 \mathrm{~s}$, $72^{\circ} \mathrm{C}$ for $1 \mathrm{~min}, 35$ cycles and $72^{\circ} \mathrm{C}$ for $10 \mathrm{~min}$. Then, $4.5 \mu \mathrm{L}$ reaction supernatants were electrophoresed on $1 \%$ agarose gel to identify the amplified products.

Electrophoresis-verified PCR products were harvested utilizing EasyPure ${ }^{\circledR}$ Quick Gel Extraction Kit5 and ligated into pMD18-T vector ${ }^{2}$ for $2 \mathrm{~h}$ at $16^{\circ} \mathrm{C}$. BL-21 competent cells of $E$. coli were transformed with the ligated complex at $37^{\circ} \mathrm{C}$ overnight.

The selected monoclonal colony was inoculated into Amp/LB liquid media $(5.0 \mathrm{~mL})$, and gently shaken for $10-14 \mathrm{~h}$ and $37^{\circ} \mathrm{C}$. Then the recombinant pMD18-T-BCoV-N plasmids were extracted using the EasyPure ${ }^{\circledR}$ Plasmid MiniPrep $\mathrm{Kit}^{5}$ and sequenced. The concentrations of plasmids were determined using Ultramicro nucleic acid protein analyzer ${ }^{6}$ after the sequencing results were identical with the sequences documented in GenBank. DNA copies were calculated based on the formula: DNA copies $=\left[6.02 \times 10^{23} \times\right.$ plasmid concentrations $\left.(\mathrm{ng} / \mu \mathrm{L}) \times 10^{-9}\right] /(660 \times$ bp of standard plasmids).

Following amplification of the recombinant standard plasmids, the positive plasmids were sequenced $^{4}$. The homogy of these sequences was compared with those in Genbank online of NCBI.

\section{Optimization of PCR reaction conditions and creation of standard curve}

QRT-PCR was performed in a $20 \mu \mathrm{L}$ reaction system [containing Premix Ex TaqTM $10 \mu \mathrm{L}$, forward primer $0.4 \mu \mathrm{L}$, reverse Primer $0.4 \mu \mathrm{L}$, TaqMan Probe $0.8 \mu \mathrm{L}$, ROX Reference Dye II $(50 \times) 0.2 \mu \mathrm{L}$, DEPC water $6.2 \mu \mathrm{L}$, plasmid template $(25 \mathrm{ng} / \mu \mathrm{L}) 2 \mu \mathrm{L}$ ].

The optimum schemes of qRT-PCR were selected from the different reaction conditions including the 10 varying primer concentrations $(12.5$, 13.0, 13.5, 14.0, 14.5, 15.0, 15.5, 16.0, 16.5 and 17.0 $\mu \mathrm{M} / \mathrm{L})$, probe concentrations $(15.0,15.5,16.0,16.5$, 17.0, 17.5, 18.0, 18.5, 19.0, 19.5 and $20 \mu \mathrm{M} / \mathrm{L})$ and annealing temperatures $(42.5,42.7,43.1,43.7,44.4$, $45.0,45.3$ and $\left.45.5^{\circ} \mathrm{C}\right)$.
Subsequently, different concentrations of recombinant plasmids (from $4.72 \times 10^{7}$ to $4.72 \times 10^{3}$ copies $(\mu \mathrm{L}$ ) were amplified with the optimized TaqMan qRT-PCR so as to acquire the amplification melting curve, standard curve and regression equation.

Specificity tests

In order to evaluate the specificity of the established TaqMan probe qRT-PCR, this assay was used to synchronously detect $\mathrm{BCoV}$ and other six viruses as BVDV, such as Japanese encephalitis virus (JEV), Classical Swine Fever Virus (CSFV), Rabies virus (RABV), Bovine Rotavirus (BRV), Bovine Parvovirus (BPV), bovine foot and mouth disease virus (FMDV). Total RNAs were extracted with the methods described above. All these viruses were provided or gifted by Lanzhou Veterinary Research Institute of the Chinese Academy of Agricultural Sciences ${ }^{7}$ or the State Ley Laboratory of Biological Engineering and Technology of the Northwest Minzu University. They were cultured in the appropriate cells, respectively. Total RNAs or DNAs were extracted using RNA or DNA kits, respectively referring to the manufacturer's protocol.

\section{Sensitivity verifications}

The sensitivity of the TaqMan probe qRT-PCR assay was assessed utilizing 10-fold dilutions (from $4.72 \times 10^{11}$ to $4.72 \times 10^{0}$ copies $/ \mu \mathrm{L}$ ) of the constructed recombinant plasmids, respectively under the optimized reaction systems. The correlated CT values were used to set the standard curves for absolute quantifications [6]. The detection results were compared with those of universal PCR so as to determine the minimum detection limit. The distilled water served as negative controls and blank. The tests were deployed in triplicate.

\section{Repeatability tests}

In order to verify the repeatability (or stability) of TaqMan qRT-PCR assay, the intra-assay and interassay repeatability were evaluated testing at least three times the same plasmids in one experiment. Intra-assay and inter-assay coefficients of variation (CVs) were calculated by dividing the standard deviation of each tested plasmid by its mean and multiplying that result by 100 , respectively.

\section{Verification of clinical specimens}

Special emphasis was placed on the suitability of the tests for rapid and reliable detection of viral 
infections in the field. Liquid or semiliquid feces specimens from 321 diarrheic calves from six different cattle herds in Gansu Province of China were detected with both TaqMan qRT-PCR and common PCR to verify the repeatability of this qRT-PCR method. They showed successively diarrhea symptoms for over 3 days. The feces specimens were collected during days 3-5 of the diarrhea.

The suspensions were prepared by diluting the feces samples according to operation instruction described above. Then, total RNA was extracted from suspensions of feces using the TIANamp Virus RNA $\mathrm{Kit}^{1}$.

\section{RESULTS}

After recombinant standard plasmids of pMD18-T-BCoV-N were amplified, the bands of agarose gel electrophoresis showed the PCR product was $699 \mathrm{bp}$, which was consistent with the predicted sizes (Figure 1). The recombinant plasmids were $99 \%$ coincidence with the sequences recorded in Genbank.

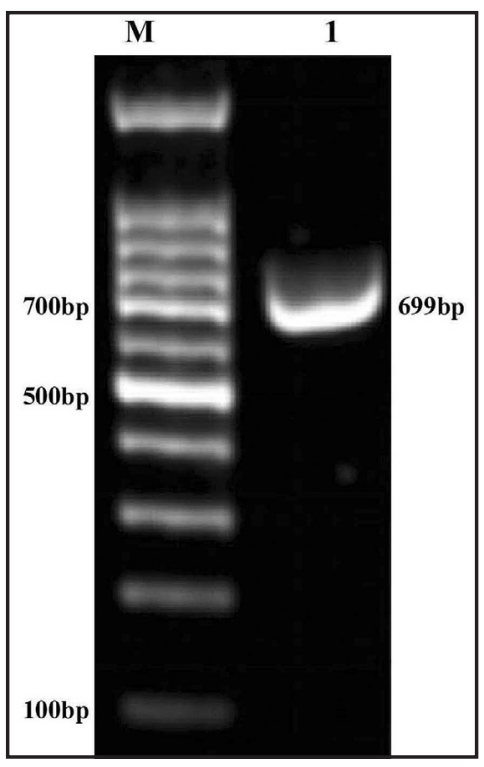

Figure 1. Amplification of pMD18-T-BCoV-N plasmids. PCR product was $699 \mathrm{bp}$, which was consistent with the predicted sizes. M: 1000 bp Marker; 1: pMD18-T-BCoV-N plasmids.

In order to find an optimum primer concentration for TaqMan qRT-PCR, the different concentrations of specific primer (BCoV-qF/BCoV-qR) were used in the experiment evaluation from 5.0 to $20.0 \mu \mathrm{M} / \mathrm{L}$ at the gradient difference of $2.50 \mu \mathrm{M} / \mathrm{L}(5.0,7.5,10.0,12.5$, 15.0, 17.5 and $20.0 \mu \mathrm{M} / \mathrm{L}$ ). The better bands were found within the primer concentrations from $12.5 \mu \mathrm{M} / \mathrm{L}$ to
17.5 $\mu \mathrm{M} / \mathrm{L}$. Afterwards, the further refinement optimization was performed with 11 primer concentrations at the gradient difference of $0.50 \mu \mathrm{M} / \mathrm{L}(12.5,13.0,13.5$, 14.0, 14.5. 15.0, 15.5, 16.0, 16.5, 17.0 and $17.5 \mu \mathrm{M} / \mathrm{L}$ ) [Figure 2A]. The optimum primer concentration for the qRT-PCR was $14.5 \mu \mathrm{M} / \mathrm{L}$.

The probe concentrations were optimized by two step processes. The first step of probe optimization was performed in the gradient of $2.50 \mu \mathrm{M} / \mathrm{L}$. As per the preliminary results of the first step. The further refinement selection was done in the gradient of 0.5 $\mu \mathrm{M} / \mathrm{L}$ (Figure 2B). The best amplification efficacy was acquired when the probe concentration was $19.5 \mu \mathrm{M} / \mathrm{L}$. The optimum reaction temperature was firstly selected from nine annealing temperatures $\left(41.0^{\circ} \mathrm{C}-51.0^{\circ} \mathrm{C}\right)$ in the tests. Then, the annealing temperatures were further optimized within $42.5^{\circ} \mathrm{C}-45.5^{\circ} \mathrm{C}$. The results showed the amplification efficacy was the greatest when the annealing temperature was at $45.0^{\circ} \mathrm{C}$ (Data omitted).

On the bases of the screen results of three parameters (primer concentration, TaqMan probe concentration and annealing temperature), we obtained that optimum conditions were $14.5 \mu \mathrm{M} / \mathrm{L}$ primer, 19.5 $\mu \mathrm{M} / \mathrm{L}$ probe and $45.0^{\circ} \mathrm{C}$ annealing temperature. Plasmid concentrations (from $4.72 \times 10^{7}$ to $4.72 \times 10^{3}$ copies $/ \mu \mathrm{L}$ ) had an excellent linear relationship with cycle threshold $(\mathrm{Ct})$ values. Dynamic curves and standard curves are shown in Figure 3. Regression equation of the standard curve was: $\mathrm{Y}=-3.425 \log \mathrm{x}+45.249$, $\mathrm{R} 2=0.9945$. Amplification efficiency was $95.856 \%$.

As shown in Figure 4, the qRT-PCR could clearly detect only $\mathrm{BCoV}$. But, all other viruses displayed no signal bands, including JEV, RABV, CSFV, BRV, BPV and FMDV. The results indicated that the established Taqman qRT-PCR had a high specificity.

After the standard plasmids were detected with this qRT-PCR assay, all plasmid concentrations from $4.72 \times 101^{1}$ to $4.72 \times 10^{1}$ copies $/ \mu \mathrm{L}$ displayed positive amplification signals (Figure 5A). However, universal PCR assay only detected $1.55 \times 10^{4}$ copies $/ \mu \mathrm{L}$ (Figure $5 \mathrm{~B})$. The findings demonstrated that the minimum detection limit of the Taqman qRT-PCR was $4.72 \times 10^{1}$ copies/ $\mu \mathrm{L}$, or 47.2 copies/ $\mu \mathrm{L}$. That was 100 -fold higher than universal PCR. Repeatability tests showed the intra-assay and inter-assay variation coefficient (VC) was $0.22 \%-10.39 \%$ and $0.08 \%-0.47 \%$ (Table 2). This demonstrated that qRT-PCR shows an excellent repeatability, or stability. 
The qRT-PCR validation was performed in 321 feces specimens harvested from six dairy farms. The results showed that $18.38 \%$ (59/321) feces samples were the positive for TaqMan qRT-PCR detection as compared to $13.39 \%(43 / 321)$ for the universal PCR. These positive specimens of TaqMan qRT-PCR contained all positive specimens of the universal PCR. The outcomes demonstrated that the sensitivity and specificity of qRT-PCR were greater than universal PCR.
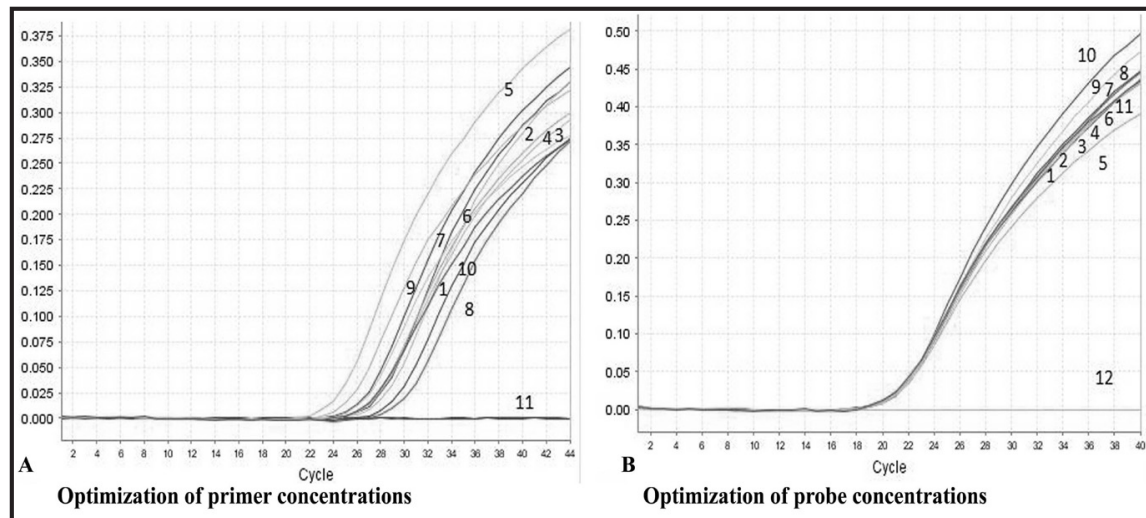

Figure 2. Optimization of primers and probe concentrations. A- Lines 1-10 represent the primer concentrations from $12.5 \mu \mathrm{M}$ to $17.0 \mu \mathrm{M}$ respectively; Line 10 represents negative control. B- Lines 1-11 represent 15.0, 15.5, 16.0, 16.5, 17.0, 17.5, 18.0, 18.5, 19.0, 19.5 and $20.0 \mu \mathrm{M}$ respectively; Line 12 represents negative control.

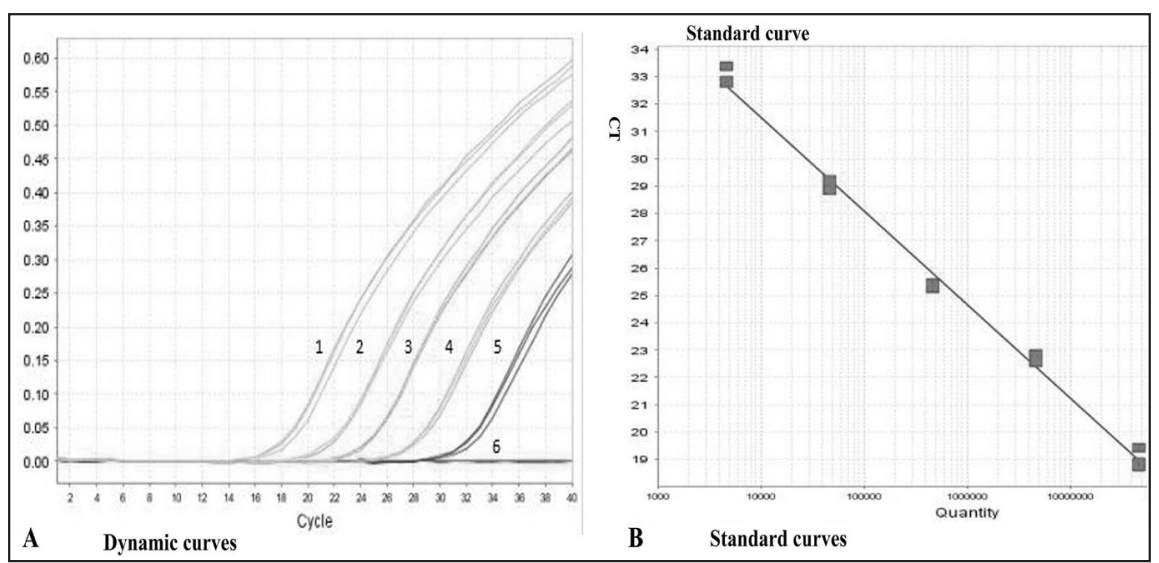

Figure 3. Dynamics curve (A) and Sstandard curve (B) of BCoV TaqMan qRT-PCR.

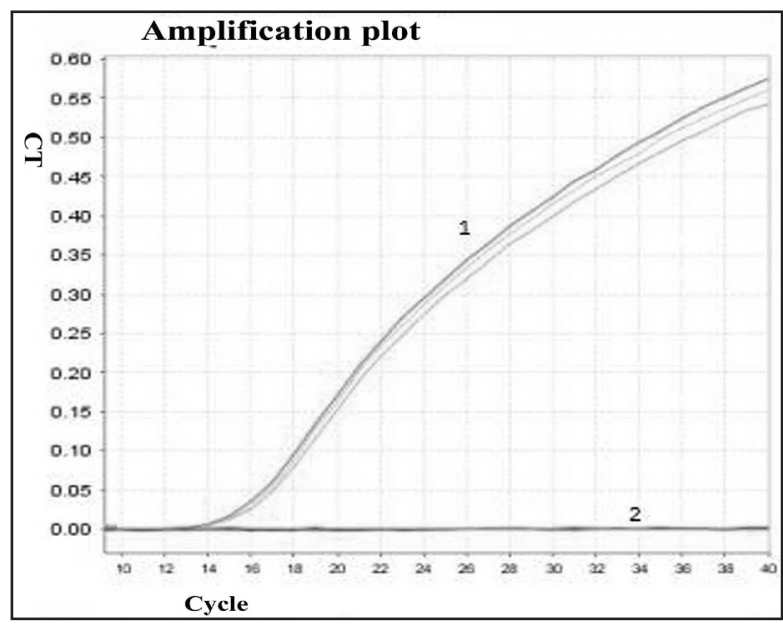

Figure 4. Specificity of TaqMan qRT-PCR. Line 1 represents BCoV; Line 2 represents control group (JEV, RABV, CSFV, BRV, BPV and FMDV) and Negative control. 


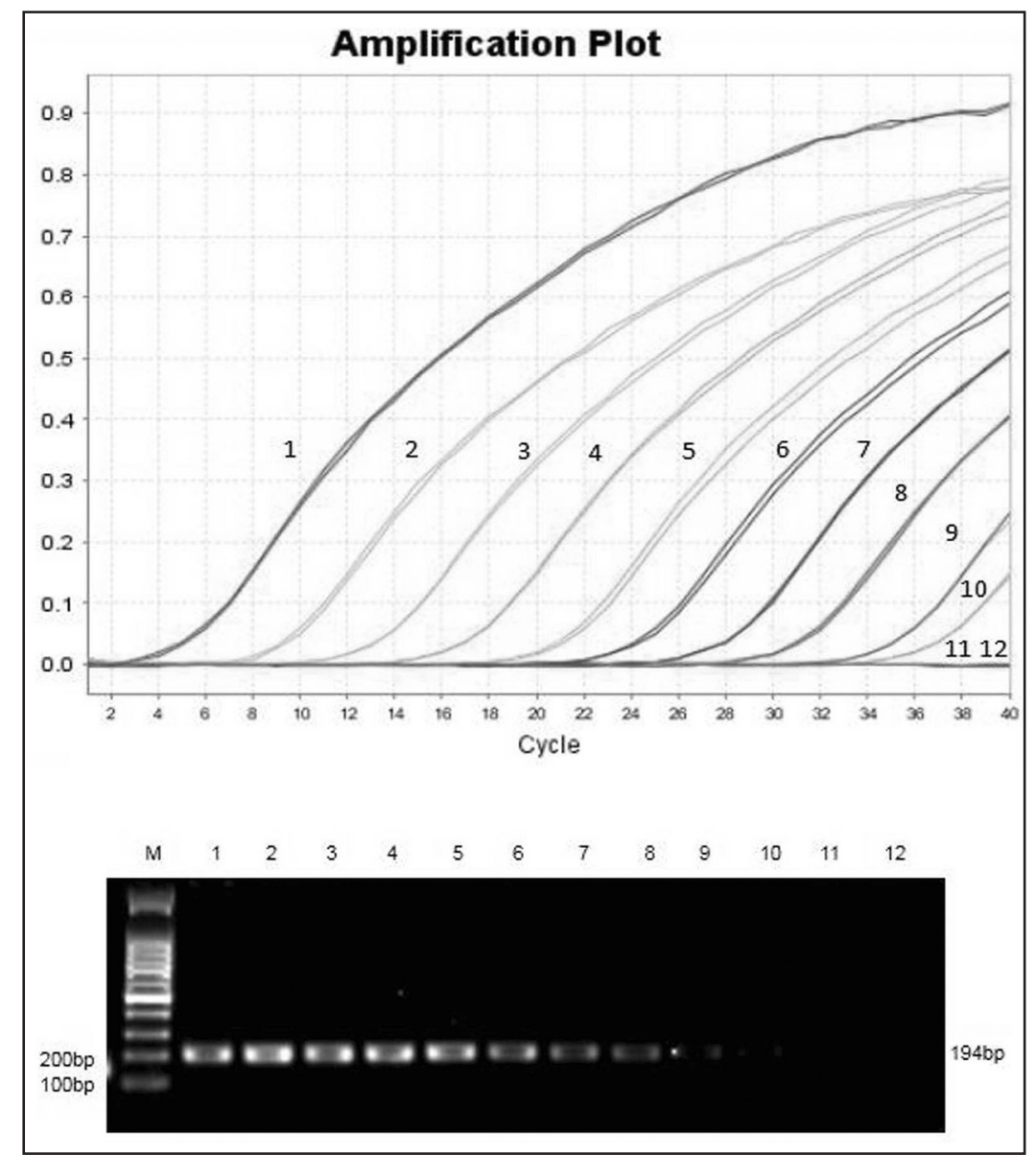

Figure 5. Sensitivity assessment of TaqMan qRT-PCR and universal PCR. Lines 1-11 represent the concentrations of recombinant plasmids pMD18-T-BCoV-N from $4.72 \times 10^{10}$ to $4.72 \times 10^{0}$ copies/ $\mu \mathrm{L}$; Line 12 represents negative control; M: 1000 bp DNA Marker.

Table 2. Repeatability of the established TaqMan probe qRT-PCR.

\begin{tabular}{ccccccc}
\hline \multirow{2}{*}{$\begin{array}{c}\text { Concentrations } \\
(\text { copies } / \mu \mathrm{L})\end{array}$} & \multicolumn{3}{c}{ Intra-assay Ct valves } & \multicolumn{3}{c}{ Inter-assay Ct valves } \\
\cline { 2 - 7 } & Mean & SD & CV $(\%)$ & Mean & SD & CV (\%) \\
\hline $4.72 \times 10^{8}$ & 12.19 & 0.04 & 0.37 & 12.13 & 0.05 & 0.39 \\
$4.72 \times 10^{6}$ & 19.96 & 0.08 & 0.39 & 19.83 & 0.09 & 0.47 \\
$4.72 \times 10^{4}$ & 27.90 & 0.04 & 0.22 & 27.93 & 0.02 & 0.08 \\
\hline
\end{tabular}

\section{DISCUSSION}

$\mathrm{BCoV}$ was detected in $18.95 \%(36 / 190)$ of the samples by reverse transcriptase polymerase chain reaction in China. These differ in the efficiency of RNA extractions, reverse transcription or PCR reactions, leading to the unstable sensitivity and specificity.

Bovine coronavirus (BCoV) was first identified during an outbreak of diarrhea among neonatal calves in the 1970s [15,21]. Earlier report demonstrated the existence of persistent infection of $\mathrm{BCoV}$ in cattle [11]. $\mathrm{BCoV}$ plays a major role in bovine diarrhea symptom.
Additionally, $\mathrm{BCoV}$ has been identified in healthy calves, which complicate the assessment of its role as a primary pathogen $[7,20]$.

In this study, we developed a quantitative real-time PCR (qRT-PCR) in this study based on the TaqMan probe of BCoV. This TaqMan qRT-PCR assay selected and used one pair of specific primers (BCoV-qF/BCoV-qR) and a specific TaqMan probe (BCoV-probe) targeting the conserved nucleocapsid (N) gene. The specificity of primers and probes was validated with Primer-BLAST. The specificity of the 
qRT-PCR was confirmed by the negative control and other six viruses, including JEV, RABV, CSFV, BRV, BPV and FMDV. The findings demonstrated that TaqMan qRT-PCR could only detect BCoV. This verified the qRT-PCR had an excellent specificity. It is obvious that this TaqMan qRT-PCR assay can detect only BCoV with stronger sensitivity and reproducibility than other real-time PCR methods $[13,16]$. The sensitivity test indicated the minimum detection limit of the TaqMan qRT-PCR was $4.72 \times 10^{1}$ copies/ $\mu \mathrm{L}$, or 47.2 copies/ $\mu \mathrm{L}$. Sensitivity of the TaqMan qRT-PCR assay was increased by 100 -fold as compared to universal PCR with a good inter-assay and intra-assay reproducibility. These outcomes are in agreement with previous studies [1,7]. Additionally, the diagnostic sensitivity and specificity were determined using 312 clinical samples from six cattle herds. The qRT-PCR showed a higher sensitivity and specificity in comparison with the conventional PCR and $89.80 \%$ concordance between the two tests was found. These outcomes were similar to earlier reports $[2,4]$.

Further, on the basis of the high sensitivity of the assay, we speculate that the qRT-PCR can be utilized to test many kinds of biological specimens and thereby be a cost-effective method to diagnose $\mathrm{BCoV}$ infections and Persistent infection cows by providing a reliable clinical examination protocol to indentify the etiologic agents of diarrhea syndrome in the dairy farms [12].

\section{CONCLUSIONS}

In conclusion, a novel TaqMan detection method for bovine coronavirus ( $\mathrm{BCoV}) \mathrm{N}$ protein had been successfully established in this work. Its minimum detection limit was $4.72 \times 10^{1}$ copies $/ \mu \mathrm{L}$ of BCoV. The sensitivity was 100 -fold higher than the universal PCR with excellent specificity and stability. This TaqMan qRT-PCR could rapidly detect BCoV and effectively identify all infected calves and cattle.
Thereby, it may be a cost-effective method to diagnose diarrhea and distinguish pathogens in dairy farms. This novel TaqMan qRT-PCR will be beneficial for enhancing diagnostic efficiency, effectively halting the spread of $\mathrm{BCoV}$ infections as well as declining the morbidity and mortality of calves.

\section{MANUFACTURERS}

${ }^{1}$ Tiangen Biochemical Technology Co. Ltd. Beijing, China.

${ }^{2}$ TaKaRa Bio Inc. Dalian, China.

${ }^{3}$ TaKaRa Bio Inc. Beijing, China.

${ }^{4}$ Transgen Biotech Company. Beijing, China.

${ }^{5}$ Thermo Fisher Scientific. Waltham, MA, USA.

${ }^{6}$ Shanghai Sangon Biotec. Shanghai, China.

${ }^{7}$ Lanzhou Veterinary Research Institute of the Chinese Academy of Agricultural Sciences, Lanzhou, China.

Authorship contributions. Miss Geng Jinjing optimized TaqMan probe qRT-PCR. Professor Gong Zhuandi took and detected the samples. Dr Li Qiongyi did the data statistics analyses. Dr Shen Xiaoyun assessed the specificity and sensitivity. Professor Wei Suocheng was responsible for the experimental designs and writing the manuscript. All authors interpreted the data, critically revised the manuscript for important intellectual contents and approved for the final version.

Funding. The work was supported by the Science and Technology Support Program project of Gansu province of China (Grant No: 1604NKCA044), the innovative research team of Yak Reproductive Regulation Mechanism and Plateau Adaptability (31920190024), the Special Fund Project for Fundamental Research Business Expenses of Central Universities, the Science and Technology Planning Project of Lanzhou, China (Grant No:2016-3-120), Chengguan district Science and Technology Planning Project of Lanzhou, China (Grant: 2016-1-1), the Innovative Team Development Project of Ministry of Education of China (IRT-17R88).

Ethical approval. All procedures referring to animal treatment were approved by the Experiment Animal Care and Use Committee of Gansu province, the People's Republic of China.

Declaration of interest. All authors have no conflicts of interest. The authors alone are responsible for the content and writing of the paper.

\section{REFERENCES}

1 Alfieri A.A., Alfieri A.F. \& Takiuchi E. 2016. Detection of Bovine Coronavirus by Conventional Reverse Transcription Polymerase Chain Reaction. Animal Coronaviruses. 3: 101-113.

2 Amer H.M. \& Almajhdi F.N. 2011. Development of a SYBR Green I based real-time RT-PCR assay for detection and quantification of bovine coronavirus. Mecular and Cellular Probes. 25: 101-107.

3 Beaudeau F., Ohlson A. \& Emanuelson U. 2010. Associations between bovine coronavirus and bovine respiratory syncytial virus infections and animal performance in Swedish dairy herds. Journal of Dairy Science. 93: 1523-1533.

4 Boileau M.J. \& Kapil S. 2010. Bovine coronavirus associated syndromes. Veterinary clinics of North America Food Animal Practice. 26: 123-146. 
5 Chaharaein B., Omar A.R., Aini I., Yusoff K. \& Hassan S.S. 2009. Detection of H5, H7 and H9 subtypes of avian influenza viruses by multiplex reverse transcription polymerase chain reaction. Microbiological Research. 164: 174-179.

6 Decaro N., Martella V., Ricci D., Elia G., Desario C. \& Campolo M. 2005. Genotypespecific fluorogenic RT PCR assays for the detection and quantitation of canine coronavirus type I and type II RNA in faecal samples of dogs. Journal of Virology Methods. 130: 72-78.

7 Gomez D.E., Arroyo L.G., Poljak Z., Viel L. \& Weese J.S. 2017. Detection of Bovine Coronavirus in Healthy and Diarrheic Dairy Calves. Journal of Veterinary Internal Medicine. 31: 1884-1891.

8 Gunn L., Collins P.J., O'Connell M.J. \& O'Shea H. 2015. Phylogenetic investigation of enteric bovine coronavirus in Ireland reveals partitioning between European and global strains. Irish Veterinary Journal. 68: 31-35.

9 Hasoksuz M., Hoet A.E., Loerch S.C., Wittum T.E., Nielsen P.R. \& Saif L.J. 2002. Detection of respiratory and enteric shedding of bovine coronaviruses in cattle in an Ohio feedlot. Journal of Veterinary Diagnostic Investigation. 14: 308-313.

10 He Q., Guo Z., Zhang B., Yue H. \& Tang C. 2019. First detection of bovine coronavirus in Yak (Bos grunniens) and a bovine coronavirus genome with a recombinant HE gene. Journal of General Virology. 100: 793-803.

11 Kanno T., Ishihara R., Hatama S. \& Uchida I. 2018. A long-term animal experiment indicating persistent infection of bovine coronavirus in cattle. Journal of Veterinary Medical Science. 80: 1134-1137.

12 Keha A., Xue L., Yan S. \& Yue H. 2019. Prevalence of a novel bovine coronavirus strain with a recombinant hemagglutinin/esterase gene in dairy calves in China. Transbound Emerging Disease. Doi: 10.1111/tbed.13228.

13 Kim J.H., Jang J.H., Yoon S.W., Noh J.Y., Ahn M.J. \& Kim Y. 2018. Detection of bovine coronavirus in nasal swab of non-captive wild water deer, Korea. Transbound Emerging Disease. 65: 627-631.

14 La Rocca S.A. 2009. A short target real-time RT-PCR assay for detection of pestiviruses infecting cattle. Journal of Virology Methods. 161: 122-127.

15 Mebus C.A., Stair E.L., Rhodes M.B. \& Twiehaus M.J. 1973. Neonatal calf diarrhea: propagation, attenuation, and characteristics of a coronavirus-like agent. American Journal of Veterinary Research. 34: 145-150.

16 Mohamed F.F., Mansour S.M., El-Araby I.E., Mor S.K. \& Goyal S.M. 2017. Mecular detection of enteric viruses from diarrheic calves in Egypt. Archives of Virology. 162: 129-137.

17 Santos N., Honma S., Timenetsky Mdo C., Linhares A.C., Ushijima H. \& Armah G.E. 2008. Development of a microtiter plate hybridization based PCR-enzyme-linked immunosorbent assay for identification of clinically relevant human group A rotavirus G and P genotypes. Journal of Clinical Microbiology. 46: 462-429.

18 Schoeman D. \& Fielding B.C. 2019. Coronavirus envelope protein: current knowledge. Virology Journal. 16: 69-72.

19 Shin J., Tark D., Le V.P., Choe S., Cha R.M. \& Park G.N. 2019. Genetic characterization of bovine coronavirus in Vietnam. Virus Genes. 55: 415-420.

20 Snodgrass D.R., Terzolo H.R., Sherwood D., Campbell I., Menzies J.D. \& Synge B.A. 1986. Aetiology of diarrhoea in young calves. Veterinary Record. 119: 31-34.

21 Symes S.J., Allen J.L., Mansell P.D., Woodward K.L., Bailey K.E. \& Gilkerson J.R. 2018. First detection of bovine noroviruses and detection of bovine coronavirus in Australian dairy cattle. Australian Veterinary Journal. 96: 203-208.

22 Traven M., Bjornerot L. \& Larsson B. 1999. Nationwide survey of antibodies to bovine coronavirus in bulk milk from Swedish dairy herds. Veterinary Record. 144: 527-529.

23 Wolff C., Emanuelson U., Ohlson A., Alenius S. \& Fall N. 2015. Bovine respiratory syncytial virus and bovine coronavirus in Swedish organic and conventional dairy herds. Acta Veterinaria Scandinavica. 57: 2-6.

24 Yan L.F., Lanny W., Pace B.B., Floyd D.W. \& Zhang S. 2016. Failed detection of Bovine viral diarrhea virus 2 subgenotype a (BVDV-2a) by direct fluorescent antibody test on tissue samples due to reduced reactivity of field isolates to raw anti-BVDV antibody. Journal of Veterinary Diagnostic Investigation. 28: 150-157.

25 Zhang Y., Liu H. \& Wang X.D. 2015. A novel real-time RT-PCR with TaqM an-MGB probes and its application in detecting BVDV infections in dairy farms. Journal of Integrative Agriculture. 14: 1637-1643.

26 Zhao J.J., Cheng D., Li N., Sun Y., Shi Z. \& Zhu QH. 2008. Evaluation of a multiplex real-time RT-PCR for quantitative and differential detection of wild-type viruses and C-strain vaccine of Classical swine fever virus. Veterinary Microbiology. 126: 1-10. 